\title{
Salvia Officinalis Extract
}

National Cancer Institute

\section{Source}

National Cancer Institute. Salvia Officinalis Extract. NCI Thesaurus. Code C71519.

An oral tablet containing an extract of the plant Salvia officinalis (common sage) with reported antihydrotic, antibiotic, antihypertensive, anti-inflammatory, antioxidant, astring ent, antispasmodic, estrogenic, and hypoglycemic properties. The primary biologically active component of common sage appears to be its essential oil which contains mainly cineol, borneol, and alpha- and beta-thujone. In addition, sage leaf contains numerous other substances including tannic acid; resins with oleic, ursonic, and ursolic acids; bitter substances with cornsole and cornsolic acid; fumaric, chlorogenic, caffeic and nicotinic acids; nicotinamide; flavones; flavone glycosides; and estrogenic substances. However, the mechanism(s) of action of common sage in the treatment of various disorders is unclear. 